\title{
Consequences of land use change on soil organic matter composition and C-P relationships in Amazonian Dark Earth and Acrisol
}

\author{
KLAUS A. JAROSCH ${ }^{1}$, LUIS CARLOS COLOCHO \\ HURTARTE ${ }^{2}$, KONSTANTIN GAVAZOV ${ }^{3}$, ALEKSANDER \\ W MUNIZ ${ }^{4}$, CHRISTOPH MÜLLER ${ }^{5}$, GERRIT ANGST ${ }^{6}$, \\ HIRAM CASTILLO-MICHEL ${ }^{7}$ AND STEFFEN A. \\ SCHWEIZER $^{8}$
}

${ }^{1}$ University of Bern

${ }^{2}$ European Synchrotron Radiation Facility (ESRF)

${ }^{3} \mathrm{WSL}$

${ }^{4}$ Embrapa Amazônia Ocidental

${ }^{5}$ Justus-Liebig University

${ }^{6}$ Biology Centre CAS

${ }^{7}$ European Synchrotron Radiation Facility

${ }^{8}$ Soil Science, TU Munich

Presenting Author: luis.colocho@esrf.fr

The conversion of tropical forest for agriculture is widely known to decrease the soil organic matter (OM) and nutrient contents of highly weathered soils in the tropics. Amazonian Dark Earth (ADE) might be more resistant due to their historical anthropogenic amelioration with e.g. charcoal, ceramics and bones, leading to higher soil $\mathrm{OM}$ and bioavailable $\mathrm{P}$ concentrations. In this study, we analyzed the effect of land use change on the OM dynamics under tropical conditions and how this is related with $\mathrm{P}$ distribution at the microscale, using ADE and an adjacent Acrisol (ACR) as model systems. Soil samples were obtained south of Manaus (Brazil), from a secondary forest and an adjacently located 40-year-old cassava plantation. The land use change induced a severe decrease of organic carbon (OC) concentrations in ADE (from 35 to $15 \mathrm{~g} \mathrm{OC} \mathrm{kg}^{-1}$ ) while OC in the adjacent ACR was less affected (18 to $16 \mathrm{~g} \mathrm{OC} \mathrm{kg}^{-1}$ ). The analysis by ${ }^{13} \mathrm{C}$ NMR spectroscopy showed that the conversion of secondary forest to cassava changed the chemical composition of OM to a more decomposed state in the ADE whereas the OM in ACR changed to a less decomposed. According to neutral sugar and lipid extraction analyses, land use change led to a larger impact on the microbial-derived and plant-derived compounds in the ADE compared to the ACR. In order to analyze the interactions of $\mathrm{OC}$ and $\mathrm{P}$ at the microscale, we conducted an incubation experiment with ${ }^{13} \mathrm{C}$ glucose for the analysis with Scanning X-ray Microscopy (SXM) and Nano scale Secondary Ion Mass Spectrometry (NanoSIMS). In both soil types, land use change caused a reduction of the total ${ }^{13} \mathrm{C}$ glucose respiration by approximately one third in a 7-days incubation, implying lower microbial activity. Microorganisms in both soil types appear to be more readily active in soils under forest, since we observed a distinct lag time between ${ }^{13} \mathrm{C}$ glucose addition and respiration under cassava planation. Preliminary results from synchrotron-based STXM demonstrate a distinct arrangement of $\mathrm{OM}$ at fine-sized charcoal-particle interfaces. From ongoing NanoSIMS analyses, we expect further insights on 